\title{
Identification and characterization of a type III secretion system in Chlamydophila psittaci
}

\author{
Delphine Sylvie Anne Beeckman ${ }^{1 * \dagger}$, Tom Geens ${ }^{1 *}$, Jean-Pierre Timmermans ${ }^{2}$, \\ Patrick Van OostveldT ${ }^{1}$, Daisy C.G. VAnRomPay ${ }^{1}$ \\ ${ }^{1}$ Department of Molecular Biotechnology, Faculty of Bioscience Engineering, Ghent University, \\ Coupure Links 653, 9000 Ghent, Belgium \\ ${ }^{2}$ Department of Veterinary Medicine, University of Antwerp, Groenenborgerlaan 171, 2020 Antwerp, Belgium
}

(Received 8 August 2007; accepted 27 December 2007)

\begin{abstract}
Chlamydiaceae are obligate intracellular Gram-negative bacteria replicating in vacuoles inside eukaryotic cells. It has been proven that most of them possess a type III secretion system (T3SS) allowing them to transfer effector molecules in the host cell. We examined the existence of a T3SS in Chlamydophila psittaci by studying the expression of three essential structural proteins $\mathrm{SctW}$, SctC, and $\mathrm{SctN}$, and one putative effector protein IncA. Immunofluorescence assays showed SctW and IncA to be associated with the bacteria and the inclusion membrane, while SctC and SctN were only localized to the bacteria itself. Immuno electron microscopy could confirm these results for SctW, IncA, and SctC. Unfortunately, SctN was not investigated with this technique. Additionally, we sequenced 14 full-length T3S genes (sccl, sctW, sctJ, sctL, sctR, sctS, scc2, copD1, sctN, sctQ, sctC, incA, ca037, and cadd) and examined the transcription of $26 C p$. psittaci T3S genes namely cluster 1 (sccl, sctW, sct $V$, sct $U$ ), cluster 2 (sctJ, sctL, sctR, sctS, sctT, scc2, copB1, copD1), cluster $3(s c t D, s c t N, \operatorname{ca037}$, sct $Q, p k n 5, s c t C)$ and non-clustered genes (incA, incC, scc3, copD2, cap1, tarp, ca530, cadd). The gene expression study indicated the T3S structural protein encoding genes to be transcribed from mid-cycle (12-18 h post infection (p.i.)) on. Genes encoding effector proteins and putative T3S related proteins were expressed early $(1.5 \mathrm{~h}-8 \mathrm{~h}$ p.i.) or late $(>24 \mathrm{~h}$ p.i.) during the developmental cycle. We hereby provided evidence for the existence of a T3SS and possible effectors in avian $C p$. psittaci.
\end{abstract}

Type III secretion / Chlamydia / Chlamydophila psittaci

\section{INTRODUCTION}

Chlamydophila (Cp.) psittaci belongs to the family Chlamydiaceae causing respiratory disease in pet birds and poultry. Pet bird owners, veterinary surgeons, and poultry workers are at risk of becoming infected by this zoonotic agent (reviewed in [1]).

Cp. psittaci is an obligate intracellular Gram-negative bacterium infecting mucosal

\footnotetext{
*These authors contributed equally to this work. ${ }^{\dagger}$ Corresponding author: delphine.beeckman@ ugent.be
}

epithelial cells. Its unique biphasic developmental cycle starts with infectious elementary bodies (EB) preferentially attaching and entrying at the base of cell surface microvilli, where they are often found in association with clathrin-coated pits. Cell entry mechanisms are not fully understood but as in Chlamydia trachomatis, type III secretion might be involved [5]. Entered EB can be found within small vesicles, avoiding fusion with lysosomes while trafficking towards the perinuclear region. EB differentiate into metabolically active reticulate bodies (RB), and binary fission within the growing vesicle results in large inclusions. Typically, 
mitochondria are surrounding these large $C p$. psittaci inclusions, most likely providing these energy parasites with the necessary additional ATP. The mechanism responsible for the recruitment of mitochondria is unknown, but again type III secretion (T3S) effector proteins might play a role. Following binary fission, $\mathrm{RB}$ differentiate into intermediate bodies (IB) and finally new infectious EB. Remarkably, newly formed EB of highly pathogenic $C p$. psittaci strains might escape from the inclusion, spreading diffusely through the cytoplasm of the host cell. From $48 \mathrm{~h}$ post infection (p.i.) onwards, cell lysis results in the release of infectious EB. However, localized rupture of the host cell membrane with the underlying inclusion emptying itself into the extracellular surroundings has been observed for highly pathogenic $C p$. psittaci strains [41]. Additionally, Chlamydiaceae are able to persist in host cells as morphologically altered $\mathrm{RB}$, which no longer divide and accumulate chromosomes [18]. Overall, Cp. psittaci modulates host cell functions to replicate or persist inside host cells but the mechanisms deployed to subvert host cell functions to benefit the pathogen are poorly understood. Given the current understanding on T3S, one could postulate a role for T3S in some, if not all stages in the $C p$. psittaci infection.

Genomics of $C$. trachomatis, $C$. muridarum, Cp. pneumoniae, and Cp. caviae $[20,27,28,34]$ revealed type III secretion system (T3SS) genes for the export of pathogenic proteins analogous to the ones identified in other gram-negative bacteria, with the Yersinia ysc-yop weaponry being the best one characterized [6]. Cp. psittaci genome sequence data are not available. Meanwhile, evidence for a functional T3SS in Cp. pneumoniae [23, 33, 36] and $C$. trachomatis [12] has been presented. Moreover, these investigators showed proteins from $C p$. pneumoniae and $C$. trachomatis, all of which had in common the presence of a large hydrophobic domain, to be secreted by a $S$. flexneri or Yersinia enterocolitica type III secretion machinery $[9,35,36]$.

The discovered chlamydial T3S machinery consists of approximately 25 proteins encoded by at least three different conserved gene clusters or pathogenicity islands. Like in other pathogens, the chlamydial T3SS probably spans the inner and outer membrane as well as the plasma membrane (during host cell attachment) or the inclusion membrane (during intracellular replication). As chlamydiae have recently been suggested to possess the most ancient non flagellar T3SS [24, 38], we have chosen to use the unified secretion and cellular translocation (Sct) nomenclature as proposed by Hueck [19] for the conserved structural proteins of the T3SS. Only chaperones and effectors were given species specific names. The exporter, located in the inner membrane of the bacterium, is presumed to consist of SctR, S, T, U, and V. The cytoplasmic membrane associated ATPase SctN, assumed to be the energizer of the system, is in close association with the exporter. The basal body, totally embedded by the exporter, would be composed of SctL, Q, D, and J, where SctJ probably connects the inner and the outer membrane proteins. The bacterial outer membrane is probably penetrated by a secretin, consisting of SctC. Normally, T3SS proteins travel across the bacterial membranes through a hollow conduit defined as the needle of the T3SS. However, needle components like SctI and SctF have not yet been identified in Chlamydiaceae. Protein translocation is supposedly mediated by the chlamydia outer proteins (Cop) B1 and D1 and assisted by specific chlamydiaceae chaperones (Scc) 1 and Scc2/Scc3, being homologous to the specific yersinia chaperones (Syc) E and D. Type III sececretion is thought to be regulated by SctW or CopN possibly acting as a cork on a flask preventing or allowing T3S proteins of being translocated across the bacterial membranes. C. trachomatis and Cp. pneumoniae are supposed to actively modify inclusion membranes with a set of T3S effector proteins, known as inclusion membrane proteins or Incs $[10,30,36]$. Additional chlamydial T3S effector proteins like the translocated actin recruiting phosphoprotein (Tarp) involved in chlamydial entry [4] and the class I accessible protein1 (Cap1), an inclusion membrane associated protein recognized by protective $\mathrm{CD}^{+} \mathrm{T}$ cells $[2,13]$, have been described, as well 
as $\mathrm{Pkn} 5$, a putative serine-threonine kinase $[11,16,17]$.

In order to examine the presence of a functional T3SS in $C p$. psittaci we sequenced 14 full-length T3S genes (sccl, sctW, sctJ, sctL, $s c t R, s c t S, s c c 2, \operatorname{cop} D 1$, sct $N$, sct $Q$, sct $C$, incA, $c a 037$, and cadd) and focused on the translation and localization of three essential structural proteins (SctW, SctC, and SctN) and one putative effector protein (IncA) using Western blotting and double-label immunofluorescence assays and immuno electron microscopy. Additionally, we examined the transcription of $26 C p$. psittaci T3S genes on the RNA level namely cluster 1 genes (sccl, sct W, $s c t V, s c t U)$, cluster 2 genes (sctJ, sct L, sctR, sctS, sctT, scc2, copB1, copD1), cluster 3 genes (sctD, sct $N$, ca037, sctQ, pkn5, sctC), and non-clustered genes (incA, inc $C$, scc3, copD2, cap1, tarp, ca530, cadd). Results were compared to those of expression studies in Chlamydia trachomatis and Chlamydophila pneumoniae.

\section{MATERIALS AND METHODS}

\subsection{Sequencing of $C p$. psittaci T3S genes}

As $C p$. abortus has in an evolutionary context been linked to the $C p$. psittaci lineage, wherein $C p$. psittaci strains resemble what might have been recent ancestors of $C p$. abortus [39], 28 putative T3S genes were identified in the at that time still unannotated $C p$. abortus genome. Subsequently, alignments (Clustal X, European Bioinformatics Institute, Hinxton, Cambridge, UK) of these loci with $C p$. caviae, Cp. pneumoniae, $C$. trachomatis, and $C$. muridarum orthologues were performed to design consensus primers by Web Primer ${ }^{1}$, with the option to amplify exact endpoints of $C p$. psittaci T3S cluster 1 ( $s c c 1, s c t W, s c t V, s c t U)$, cluster 2 (sctJ, sctL, sctR, sctS, sct T, scc2, copB1, copD1), cluster 3 (sctD, sctN, ca037, sctQ, pkn5, sctC), and non-clustered genes (incA, incB, inc $C$, scc $3, \operatorname{cop} B 2$, copD2, cap1, tarp, ca530, cadd). Ca037 is the orthologue of the CCA00037 protein in Cp. caviae. $\mathrm{Ca} 530$, being the orthologue of another $C p$. caviae

${ }^{1}$ Web Primer: DNA and Purpose Entry [on line] (1997-2007) http://seq.yeastgenome.org/cgibin/web-primer [consulted 19 December 2007]. protein (CCA00530) was included because its gene expression may be subject to phase variation [37]. Primer sequences are given in Table I.

Cp. psittaci genotype D strain 92/1293 was grown in BGM cells and infections were carried out as described previously [40]. Genomic DNA was extracted as described by Wilson et al. [43] and putative $C p$. psittaci T3S genes were PCR amplified and ligated into $\mathrm{pGEM}^{\circledR}{ }_{-} \mathrm{T}$ (Promega, Leiden, The Netherlands) for sequencing.

Obtained gene sequences were compiled and analyzed with Clustal X (European Bioinformatics Institute), while predicted translation products were further analyzed with Simple Modular Architecture Research Tool (SMART 5, European Molecular Biology Laboratory, Heidelberg, Germany) revealing specific domains, repeats and motifs [22] and Conserved Domain Architecture Retrieval Tool (CDART, National Center for Biotechnology Information, Bethesda, MD, USA) examining protein similarities across significant evolutionary distances [15]. IncA and SctW were examined for possible serine, threonine, and tyrosine phosphorylation sites with the NetPhos server (version 2.0, Center for Biological Sequence Analysis, Lyngby, Denmark) [3].

\subsection{Expression of SctW, SctC, SctN, and IncA and antibody production}

We intended to prove the expression of a T3SS in the highly pathogenic $C p$. psittaci genotype D strain $92 / 1293$ before going to transcription studies of T3S genes. Therefore, we focused on SctW as presumed T3S regulator, SctC probably penetrating the outer membrane, SctN as putative T3S energizer and finally IncA as a well-known T3S effector protein. In order to construct SctW, SctC, SctN, and Inc A gene products possessing histidine-containing (HT) N-terminal leader sequences, purified PCR products were ligated into pET-30 Ek/LIC (Novagen, VWR, Leuven, Belgium) followed by heat-shock transformation of E. coli BL21(DE3) cells and induction with $0.1 \mathrm{mM}$ IPTG (Promega). HT-proteins were purified (Talon Spin Columns, BD Biosciences, Erembodegem, Belgium) and identified by mass spectroscopy. Only SctWHT, SctC-HT, and IncA-HT were successfully expressed. Probability based Mowse scores as determined by the Mascot server [25] were respectively 77, 66, and 60. HT-leaders were removed using the Novagen enterokinase cleavage kit. 
Table I. Primer sequences for amplification of full length $C p$. psittaci TTS genes.

\begin{tabular}{|c|c|c|c|c|}
\hline Cluster & Gene & Forward primer sequence $^{\mathrm{a}}$ & Reverse primer sequence $^{\mathrm{b}}$ & Size (bp) \\
\hline \multirow[t]{4}{*}{ Cluster 1} & sccl & ATGCAAAATCAGTTTGAACAAC & TTATAAATGATACATGCCTAGGACA & 441 \\
\hline & $s c t W$ & ATGGCTGCATCTGGAGGA & TTAAGACCAGGGATAAGGTTTG & 1202 \\
\hline & $s c t V^{\mathrm{c}}$ & ATGAATAAGCTACTCAATTTTGTC & TTAGAAAATCTGAATTCTTCCTAA & 2130 \\
\hline & $s c t U$ & ATGGGTGAAAAAACAGAAAAGG & TTATAGATTATCGGGTTGGTTAATG & 1083 \\
\hline \multirow[t]{8}{*}{ Cluster 2} & sctJ & ATGTTTCGTAGTTCTATTTCTTG & CTAGACACCCTCATTTTCTTCG & 943 \\
\hline & $\operatorname{sct} L$ & ATGAAGTTTTTTAGTCTAATTTTTAAACATGAC & TTATTCTTGCTTGTTCTGAGCTTC & 657 \\
\hline & $s c t R$ & ATGCGTTTCATTTTTCGTACT & CTATTTAAAGCTAATCATGAGACCT & 918 \\
\hline & sct $S$ & GTGATAGCACTCGCCGCAA & TTATTTCCATTTATAAAAGTTTTGGAAGA & 285 \\
\hline & sct $T$ & ATGGCAATCTCTTTACCAGAGC & CTAAAGGACTTTAGGATTAGATCCG & 870 \\
\hline & $\operatorname{scc} 2$ & ATGAGCAAGCCTACTTCAAATAATTC & TTAATTTTTTTTTCCGGAGTTT & 684 \\
\hline & $\operatorname{copB1}$ & ATGTCTCTTTCTACCTCAGGTCCA & TTATACTGCTGATGCTAAGCCT & 1485 \\
\hline & copD1 & ATGACATCAGGAGTTAGTGGAA & TTAGCTAAAGATTGCAGAAGTTG & 1323 \\
\hline \multirow[t]{6}{*}{ Cluster 3} & $s c t D$ & $/^{\mathrm{d}}$ & / & \\
\hline & $\operatorname{sct} N$ & ATGGAWGAGTTMMMRGACAGATTTCG & TCYTTAACAACYTTYTCTGC & 1329 \\
\hline & $c a 037$ & ATGGAATTAAATAAAACATCCGAG & TTATAAACGTGCTTCTTCAACTT & 846 \\
\hline & $\operatorname{sct} Q$ & ATGACAGTAGCAGCGGAACCTA & TTAGACTTCTAGAACTCGAATTCCT & 1116 \\
\hline & pkn5 & $/^{\mathrm{d}}$ & / & \\
\hline & $\operatorname{sct} C$ & TTAAAAGGGAAACAAATTACTTGTG & TTATTGAGCTTCTATTTCTAGCATT & 2730 \\
\hline \multirow{10}{*}{$\begin{array}{l}\text { Non- } \\
\text { clustered }\end{array}$} & inc $C$ & ATGACCTCTGTAAGAACCGATTT & TTAATTCCCTGTTAATCTCGTTTCG & 555 \\
\hline & incB & ATGTCAACAACCACGCCATT & TCAAGCTTCTATTTGAGAATTGT & 609 \\
\hline & incA & ATGACATCGACGGTAGAATCTGCT & TTACTGGTCATATATTGGGAA & 1143 \\
\hline & $\operatorname{scc} 3$ & ATGTCACCAAGCACGCTCC & TTATGCATGGTTTTTTATATCCAAG & 597 \\
\hline & $\operatorname{cop} B 2$ & ATGTCTTCCTGGCTCGCA & TTACTTTAGAGATTCCAGAAACGT & 1515 \\
\hline & $\operatorname{copD} 2^{\mathrm{c}}$ & ATGACAGCATCTTGTGCAGTAACAG & CTATTGGTAGAGGCTGCGAACA & 1479 \\
\hline & capl & ATGGCATCTGTAACACCACAAG & TTATGAATGAGCCCATGCG & 975 \\
\hline & $\operatorname{tarp}^{c}$ & ATGTCGAGTCCAATTAATAATCAGC & CTACGAGCGCCGTTGTGG & 2613 \\
\hline & $\operatorname{ca} 530^{\mathrm{c}}$ & ATGCCAGGAATTATTTTACATTCCC & CTAATTCAGCGTTCTTTCTCCTGTC & 1623 \\
\hline & cadd & ATGAAGGAGAGGATTTATACGGTCC & TTAATGACCGCAATTACAACGAC & 807 \\
\hline
\end{tabular}

a All forward primers carry the GACGACGACAAG adaptor at the $5^{\prime}$ end.

${ }^{\mathrm{b}}$ All reverse primers carry the GAGGAGAAGCCCGGT adaptor at the $5^{\prime}$ end.

${ }^{\mathrm{c}}$ No amplicon obtained.

${ }^{\mathrm{d}}$ No working full length primers were designed.

Female New Zealand White rabbits were subcutaneously immunized with recombinant SctW, SctC, or IncA according to internationally recognized guidelines. Animal experiments were approved by the local ethical committee (reference number: EC 2005/12). Sera were tested in ELISA and Western blotting using recombinant proteins and cell lysate of Cp. psittaci 92/1293 (serovar D), GR9 (serovar C), or $84 / 55$ (serovar A) infected and uninfected BGM cells. For all strains a band at the predicted molecular weight could be observed. There was no crossreactivity of the generated polyclonal antibodies against $C$. muridarum, $C$. trachomatis, $C p$. abortus, $C p$. felis, or $C p$. pneumoniae purified EB and RB. For SctN, Cp. pneumoniae cross-reacting mouse anti-SctN (kindly obtained from R. Lugert, Germany) was used in further experiments.

\subsection{Western blotting}

BGM cells at a concentration of $2 \times 10^{5}$ per $\mathrm{mL}$, which were either infected or left uninfected, were solubilized in SDS sample buffer containing 2.5\% $\beta$-mercaptoethanol and boiled for $5 \mathrm{~min}$. Aliquots of $20 \mu \mathrm{L}$, taken at $15 \mathrm{~min}, 5 \mathrm{~h}, 22 \mathrm{~h}, 30 \mathrm{~h}$, and $48 \mathrm{~h}$ p.i. were separated by SDS-PAGE as described by Laemmli [21] followed by immunoblotting with rabbit polyclonal anti-SctC, -SctW, and -IncA, and mouse polyclonal anti-SctN [23]. Biotin-labeled anti-rabbit (Molecular Probes, 
Invitrogen, Merelbeke, Belgium) or anti-mouse antibodies (Amersham Biosciences, GE Healthcare, Diegem, Belgium) followed by horseradish peroxidase-labeled streptavidin (Zymed, Invitrogen) and 3-amino-9-ethylcarbazole (AEC, Sigma, Bornem, Belgium) were used for visualization.

\subsection{Double-label fluorescence microscopy}

To determine the translation and localization of SctC, SctN, SctW, and IncA during the developmental cycle, fluorescence double-labeling experiments were conducted from 1 till $50 \mathrm{~h}$ p.i. using a $5 \mathrm{~h}$ time interval. All dilutions and washing steps (three) were performed with $1 \%$ BSA in PBS. BGM cells were grown and infected with $C$ p. psittaci 92/1293 (MOI 13) as described previously [42]. At each time point, infected monolayers were fixed with methanol and blocked with $5 \%(\mathrm{w} / \mathrm{v})$ FCS in PBS. Cell layers were first incubated with anti-SctC, anti-SctN, anti-SctW or anti-IncA for $1 \mathrm{~h}$ at $37^{\circ} \mathrm{C}$, rinsed and then incubated with the FITC-labeled anti-rabbit IgG second antibody (Dako, Heverlee, Belgium) for SctC, SctW, and IncA detection or the Alexa Fluor 546labeled anti-mouse IgG second antibody (Dako) for SctN detection. Cell layers for SctC, SctW, and IncA detection were rinsed and subsequently bacteria were labeled with a MOMP-specific mouse monoclonal antibody (MAb) 7B6III [14], while bacteria in cell layers for SctN detection were labeled with an anti-92/1293 rabbit polyclonal antibody. Hereafter, monolayers were rinsed and finally, labeling of the bacteria with the MAb 7B6III or with the anti-92/1293 rabbit polyclonal antibody could be visualized by using the Alexa Fluor 546-labeled anti-mouse IgG and the FITC-labeled anti-rabbit IgG, respectively. Fluorescent images were acquired with a $60 \times$ apochromat objective of a confocal laser scanning microscope (Radiance 2000, Bio-Rad, Nazareth, Belgium).

\subsection{Immuno electron microscopy}

Cp. psittaci 92/1293 infected and mock infected (negative control) BGM monolayers seeded on thermanox slides were used. At $15 \mathrm{~min}, 5,22,30$, and $46 \mathrm{~h}$ p.i. the medium was gently aspired and the monolayers were immersed in $1 \mathrm{~mL}$ fixative ( $2 \%$ paraformaldehyde $+0.05 \%$ glutaraldehyde in $0.1 \mathrm{M}$ phosphate buffer) (Sigma) for $2 \mathrm{~h}$ at $4{ }^{\circ} \mathrm{C}$ and subsequently rinsed overnight in phosphate buffer at $4{ }^{\circ} \mathrm{C}$. Next, they were dehydrated in a graded concentration series of ethanol (70, 90, $95 \% ; 15$ min each $+3 \times 100 \% ; 30$ min each) at RT. The blocks were then impregnated with LR White resin $\left(2 \times 1 \mathrm{~h}+\right.$ overnight at $\left.4{ }^{\circ} \mathrm{C}\right)$ (Electron Microscopy Science, Hatfield, UK). After polymerization at $4{ }^{\circ} \mathrm{C}$, ultrathin sections $(\sim 70 \mathrm{~nm})$ were cut on an Ultracut UCT cryomicrotome (Leica Microsystems, Groot-Bijgaarden, Belgium). Sections were transferred to formvar-coated copper grids (Gilder, Laborimpex, Brussels, Belgium), and pretreated with $0.1 \%$ glycine in tris-buffered saline (TBS) for $10 \mathrm{~min}$ at RT, followed by a $2 \times 5$ min rinse in the same buffer solution, and subsequently a $30 \mathrm{~min}$ pre-treatment with $10 \%$ normal goat serum (Dako) in $0.03 \mathrm{M}$ TBS and $0.1 \%$ coldwater fish gelatin (Sigma). Incubation with the primary rabbit antisera (SctW (1/50), SctC $(1 / 50)$, and IncA $(1 / 200))$ lasted for $17 \mathrm{~h}$ at $4{ }^{\circ} \mathrm{C}$. The rabbit pre-immunization serum $(1 / 50)$ was used as negative control. After rinsing, the sections were exposed to gold-conjugated goat anti-rabbit IgG (GAR/G20; British BioCell, Cardiff, UK, diluted $1 / 20$ ) for $2 \mathrm{~h}$ at RT. Finally, after rinsing in TBS $(2 \times 5 \mathrm{~min})$ and BiDest $(10 \times 2 \mathrm{~min})$, the sections were postfixed with $2 \%$ glutaraldehyde $(1 \times 5 \mathrm{~min})$ and contrasted with uranyl acetate and lead citrate. Examination was done with a Philips CM10 transmission electron microscope at $80 \mathrm{kV}$ (FEI Systems, Eindhoven, The Netherlands).

\subsection{T3S gene expression analysis}

Total RNA from $2 \times 10^{5}$ infected BGM cells (MOI 13) was prepared using the Total RNA Isolation Reagent (TRIR, ABgene, Westburg, Leusden, The Netherlands) according to the manufacturer's protocol. RNA from uninfected cells served as a negative control. After RNA extraction, samples were treated with RNase-free amplification grade DNase I (Promega) following the manufacturer's instructions and were confirmed to be DNA-free by performing a PCR for the Cp. psittaci $16 \mathrm{~S}$ rRNA gene. Half a microgram of total RNA was reverse transcribed for $2 \mathrm{~h}$ at $47^{\circ} \mathrm{C}$ using selective hexamers (5'TTANNN3' $5^{\prime} 5^{\prime}$ CTANNN3'). Reverse transcription was followed by an incubation at $75^{\circ} \mathrm{C}$ for $10 \mathrm{~min}$. Each RNA sample was spiked with $5 \mathrm{ng}$ coliphage MS2 control present in the Reverse-IT ${ }^{\text {TM }} 1$ st Strand Synthesis Kit (ABgene). A reverse transcriptase minus control was performed 
Table II. Oligonucleotide primers used for RT-qPCR analysis.

\begin{tabular}{|c|c|c|c|c|c|c|}
\hline Cluster & Gene & Forward primer sequence & $\mathrm{N}^{\mathrm{a}}$ & Reverse primer sequence & $\mathrm{N}$ & Size (bp) \\
\hline \multirow[t]{4}{*}{ Cluster 1} & sccl & ACTTCGGGAAACATTGCTGT & 0 & TGCCTAGGACATGTAGATCAGG & 0 & 292 \\
\hline & $\operatorname{sct} W$ & CATGATTCGGGATTCTCAGG & 0 & CAATACCTTGAAGGGCAGGA & 0 & 302 \\
\hline & $\operatorname{sct} V$ & CAGTAGAACCTTTGGGGGAGA & 0 & CAAAGCCACCATCAATAGGAA & 0 & 181 \\
\hline & $\operatorname{sct} U$ & GGAAAAGTTTGAGGTTAAACAGGA & 0 & TTTCCTTCATCCCAAAGCTG & 0 & 315 \\
\hline \multirow[t]{8}{*}{ Cluster 2} & sctJ & TTAAACGCTTGGTTGCCAGT & 0 & TGGATCGAAGAACCCTTTTG & 0 & 299 \\
\hline & sctL & GGCTTTTTCAGCTCTGCTTG & 0 & GAAACAATGGCTTCTGGATGA & 0 & 288 \\
\hline & $\operatorname{sct} R$ & ACGCAATACGCCAAAAAGTC & 0 & CAACCATCCACCATCACAAC & 0 & 291 \\
\hline & $\operatorname{sct} S$ & ACTCGCCGCAAGCTTTAGAT & 0 & GGAAGATTTGAGAAGCAAAACG & 0 & 254 \\
\hline & $\operatorname{sct} T$ & TCNCCTCATGGGATCTTCTATC & 1 & TGAAGGCTTTCAANGCAGAA & 1 & 322 \\
\hline & $s c c 2$ & CCGGATTAACTCTCCAGCAA & 0 & CTTCGGTTTGGTCGATCTTC & 0 & 303 \\
\hline & copB1 & TCTACACCNCAAGCTGTACCC & 1 & AGAGTGGTCTCNAATGTTTTGTT & 1 & 323 \\
\hline & $\operatorname{copDl}$ & GGTCCCAAAGGACTTCAACA & 0 & CCCGAGATCATGCTTTGTTT & 0 & 299 \\
\hline \multirow[t]{6}{*}{ Cluster 3} & $\operatorname{sct} D$ & GCAGCTCANGAAGAAGAAGAAA & 1 & TGATGAAAGACAAAGCNTCCA & 1 & 310 \\
\hline & $\operatorname{sct} N$ & TGATGGTCACGTTGTCTCGT & 0 & TTGCGAGGCTTCCTCATAAT & 0 & 301 \\
\hline & $c a 037$ & TCCAGTGAGGTTGTTGTGGA & 0 & AACCAGCAAGCTGAGAAGGA & 0 & 301 \\
\hline & $\operatorname{sct} Q$ & TGCGGATTAGACGGAAAAAC & 0 & TCAACAAAACGACCACCAAA & 0 & 299 \\
\hline & $p k n 5$ & CTTCGTAAGTCAATGGGGTCA & 0 & CCATCACCTATTTCCCATGC & 0 & 291 \\
\hline & $\operatorname{sct} C$ & CTTGCAAGTCCCTGATGGTT & 0 & GGGGTGTTGACATTCAGGAG & 0 & 298 \\
\hline \multirow{8}{*}{$\begin{array}{l}\text { Non- } \\
\text { clustered }\end{array}$} & inc $C$ & TGACCTCTGTAAGAACCGATTT & 0 & GCCATAGGACCNCTGCAA & 1 & 320 \\
\hline & incA & AACATGGTGGATGCTGTGAA & 0 & TCTGCCGTTTCTGTGGTAGA & 0 & 299 \\
\hline & $\operatorname{scc} 3$ & TTTCCNGATGATTTGGANAGTT & 2 & GCATANGCATGTAAAGCTTGNG & 2 & 275 \\
\hline & $\operatorname{copD} 2$ & CCAAGAGCAACAACANCATAAA & 1 & TTAGCTTGACTTTCNTAACTTTCAA & 1 & 309 \\
\hline & capl & CCTANATGATGACAGCNAACCA & 1 & GCCAANCGAACTGAAGCAG & 1 & 283 \\
\hline & tarp & CAACAGCAGAGCAAGCNGTA & 1 & ACAGANGGGGTGGATAGGAA & 1 & 493 \\
\hline & $\operatorname{ca5} 30$ & GCCGNTGTCATGCTTCNTAT & 2 & NCGTATNTCTTGAATAGTNAGNTGC & 4 & 315 \\
\hline & cadd & CAATCAAAAACACATGTTAAACCA & 0 & TTGAGCTGCTGCACTAGGAA & 0 & 301 \\
\hline \multirow[t]{3}{*}{ Normalizing } & $16 s$ & GTCAAGTCAGCATGGCCCTT & 0 & CCCAGTCATCAGCCTCACCT & 0 & 300 \\
\hline & $r s b V 2$ & GAAGGNGCGTTAGATGCTGT & 1 & CATTCTGTTCTGATTGGCANA & 1 & 333 \\
\hline & $M S 2$ & UNKNOWN SEQUENCE & 0 & UNKNOWN SEQUENCE & 0 & 462 \\
\hline
\end{tabular}

${ }^{\mathrm{a}} \mathrm{N}$ represents the number of degenerations per primer.

to check for DNA contamination. All the experiments were performed twice.

Following cDNA synthesis, cDNA amplification was performed for 26 T3S genes, the $C p$. psittaci 16S rRNA normalization gene and the MS2 spike using the Absolute ${ }^{\mathrm{TM}}$ QPCR SYBR ${ }^{\circledR}$ Green Mix (ABgene). The DNA polymerase was initially activated for $15 \mathrm{~min}$ at $94^{\circ} \mathrm{C}$. Then 55 cycles of amplification were carried out according to the following protocol: cDNA was denatured at $94^{\circ} \mathrm{C}$ for $20 \mathrm{~s}$, primers (Tab. II) annealed at $55-60^{\circ} \mathrm{C}$ for $30 \mathrm{~s}$ and extended at $72^{\circ} \mathrm{C}$ for $40 \mathrm{~s}$ with a final incubation at $72{ }^{\circ} \mathrm{C}$ for $10 \mathrm{~min}$. Program settings included acquisition on the FAM/Sybr channel in the extension step and a gain of six. Quantification was done by using standard graphs of the cycle threshold $(\mathrm{Ct})$ values obtained by testing tenfold serial dilutions $\left(10^{6}\right.$ to $10^{3}$ molecules $/ \mu \mathrm{L}$, except for $16 \mathrm{~S}$ rRNA: $10^{9}$ to $10^{1}$ molecules $/ \mu \mathrm{L}$ for normalizing purposes) of the purified PCR products. All samples and standards were tested in duplicate. Ctvalues of the samples were automatically converted into initial template quantities $\left(\mathrm{N}_{0}\right)$ by use of the RotorGene Software 6.0 (Westburg) using imported 


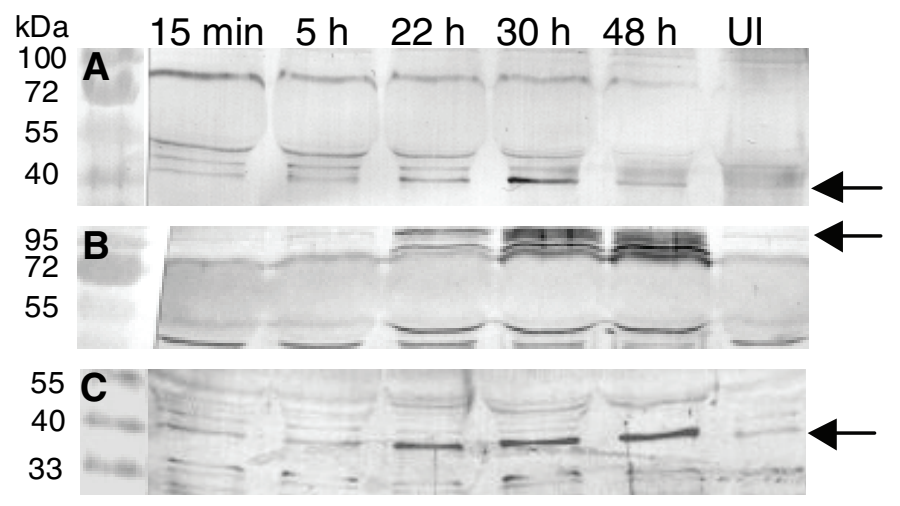

Figure 1. Detection of chlamydial proteins (SctC, SctW, IncA) by immunoblotting. Proteins from whole cell lysates of Cp. psittaci 92/1293 infected (different timepoints) or uninfected (UI) BGM-cell monolayers were resolved in $12 \%(\mathrm{w} / \mathrm{v})$ acrylamide gels. Immunoblotting was performed with anti-sera generated in rabbit. Proteins were visualized by probing with biotin labeled anti-rabbit antibodies, streptavidine-HRP and development with AEC. Arrows indicate the bands at the expected molecular masses: A: SctW (43 kDa), B: SctC $(99.5 \mathrm{kDa}), \mathrm{C}:$ IncA $(41.8 \mathrm{kDa})$.

standard curves from previous runs. Quantification results of the coliphage MS2 RNA were used to correct for inter-sample variability, while quantification results of the chlamydial $16 \mathrm{~S}$ rRNA were used to correct for bacterial growth during the developmental cycle. In order to use multiple messages for normalization, we additionally evaluated $r s b V 2$, relatively constantly expressed during the C. trachomatis developmental cycle from $1 \mathrm{~h}$ to 48 h p.i. [8]. Unfortunately, $C p$. psittaci rsbV2 was only expressed from $12 \mathrm{~h}$ p.i. onwards and could therefore not be used for normalization. Expression categories were defined as early (1.5-8h p.i.), middle (12-18 h p.i.) and late (by $24 \mathrm{~h}$ p.i.).

To compare the two independent samples (gene expression ratios of 26 genes from two independent infection experiments, each $16 \mathrm{~S}$ rRNA normalized) at the same timepoint, a Paired Student's T-test was used (SPSS Inc., Chicago, IL, USA). Secondly, an analysis of variance (ANOVA, SPSS Inc.) with post hoc analysis was performed along the time axis to determine significant upregulation time points for each gene.

\section{RESULTS}

\subsection{Sequencing of $C p$. psittaci $\mathrm{T} 3 \mathrm{~S}$ genes}

The following 14 full-length T3S genes were successfully sequenced: cluster 1 genes $s c c 1$ and sctW, cluster 2 genes sctJ, sctL,
sctR, sct $S$, scc2, and copD1, cluster 3 genes $s c t N, \operatorname{ca037}, s c t Q$, and sctC, and finally the non-clustered T3S genes incA and cadd. An overview of the properties and similarities of these 14 full-length $C p$. psittaci T3S genes as defined by SMART and CDART is shown in Table III. The NetPhos server predicted 27 possible phosphorylation sites for $C p$. psittaci IncA and 30 for $\mathrm{SctW}$. We aligned the four $C p$. psittaci IncA sequences available in GenBank ${ }^{\circledR}$ (National Center for Biotechnology Information) with our own genotype D strain Cp. psittaci 92/1293 IncA sequence at both the DNA and protein level. Protein identity varied from $99.0 \%$ (with strain NJ1 belonging to the same genotype D) to $96.1 \%$ (with VS225, a genotype F strain) and similarity was between $99.2 \%$ (again with NJ1) and $96.6 \%$ (with both VS225 and CP3, the latter being a genotype B strain).

\subsection{Western blotting}

Western blot studies indicated SctW, SctC, SctN, and IncA to be expressed by $C p$. psittaci strain 92/1293. Protein bands corresponding to the expected masses of SctW (43 kDa), SctC (99.5 kDa), SctN (48.3 kDa), and IncA $(41.8 \mathrm{kDa})$ were first detected at $15 \mathrm{~min}, 22 \mathrm{~h}$, $48 \mathrm{~h}$, and $22 \mathrm{~h}$ p.i., respectively (Fig. 1). For

(page number not for citation purpose) Page 7 of 18 
Table III. Properties and similarities of the 14 full-length $C p$. psittaci T3S genes. Properties and Genbank accession numbers of genes sequenced in this study, as defined by SMART and CDART analysis of in silico generated protein sequences (AA stands for amino acids). Homologies of the sequenced T3S genes to those in other Chlamydiaceae are presented as the percentage of sequence identity with the corresponding gene in either $C p$. pneumoniae or $C$. trachomatis.

\begin{tabular}{|c|c|c|c|c|c|c|}
\hline$\overline{\text { Cluster }}$ & Gene & Protein & Properties and similarities as defined by SMART and CDART & $\begin{array}{l}\% \text { identity with } \\
\text { Cp. pneumoniae }\end{array}$ & $\begin{array}{l}\% \text { identity with } \\
\text { C. trachomatis }\end{array}$ & $\begin{array}{c}\text { Accession } \\
\text { number }\end{array}$ \\
\hline \multirow[t]{2}{*}{$\overline{\text { Cluster } 1}$} & sccl & $\begin{array}{l}\text { Specific chlamydia } \\
\text { chaperone } 1\end{array}$ & $\begin{array}{l}146 \text { AA. Similarity with enteropathogenic } E \text {. coli (EPEC) } \\
\text { CesT, as a chaperone for the T3SS translocated intimin } \\
\text { receptor (Tir). Absence of transmembrane domains. }\end{array}$ & 69.1 & 66.2 & DQ299384 \\
\hline & $\operatorname{sct} W$ & $\begin{array}{l}\text { Secretion and cellular } \\
\text { translocation protein } \mathrm{W}\end{array}$ & $\begin{array}{l}398 \text { AA, low complexity regions at positions } 2 \text { to } 35 \text { and } 116 \text { to } \\
\text { 133. Classified in the InvE family of Salmonella spp. invasion } \\
\text { proteins by CDART. }\end{array}$ & 65.8 & 55.2 & DQ299385 \\
\hline \multirow[t]{6}{*}{ Cluster 2} & sct $J$ & $\begin{array}{l}\text { Secretion and cellular } \\
\text { translocation protein } \mathrm{J}\end{array}$ & $\begin{array}{l}330 \mathrm{AA} \text {, low complexity regions at positions } 57 \text { to } 67,237 \text { to } \\
251 \text {, and } 289 \text { to } 301 \text {, transmembrane domain at position } \\
\text { 238-260. Similarity with the Yersinia secretion protein } \mathrm{J} \text { (YscJ) } \\
\text { and the flagellar biosynthesis protein FliF. }\end{array}$ & 74.3 & 71.2 & DQ299387 \\
\hline & sct $L$ & $\begin{array}{l}\text { Secretion and cellular } \\
\text { translocation protein } \mathrm{L}\end{array}$ & $\begin{array}{l}229 \text { AA, coiled-coil at position } 35 \text { to } 93 \text {. Similarity with the } \\
\text { flagellar biosynthesis protein FliH. }\end{array}$ & 70.9 & 67.2 & DQ299388 \\
\hline & $s c t R$ & $\begin{array}{l}\text { Secretion and cellular } \\
\text { translocation protein } \mathrm{R}\end{array}$ & $\begin{array}{l}305 \text { AA, transmembrane regions at positions } 4 \text { to } 26,92 \text { to } 114 \text {, } \\
134 \text { to } 156,246 \text { to } 268 \text {, and } 278 \text { to } 300 \text {. Similar to the flagellar } \\
\text { biosynthesis proteins FliP and FliO. }\end{array}$ & 72.2 & 69.6 & DQ299389 \\
\hline & $s c t S$ & $\begin{array}{l}\text { Secretion and cellular } \\
\text { translocation protein } S\end{array}$ & $\begin{array}{l}94 \text { AA, transmembrane domains at positions } 21 \text { to } 43 \text { and } 53 \text { to } \\
75 \text {, low complexity region at position } 19 \text { to } 36 \text { within the first } \\
\text { transmembrane domain. Similarity with E. coli secretion } \\
\text { protein } S \text { (EscS). }\end{array}$ & 77.4 & 75.4 & DQ299390 \\
\hline & $s c c 2$ & $\begin{array}{l}\text { Specific chlamydia } \\
\text { chaperone } 2\end{array}$ & $\begin{array}{l}227 \text { AA, low complexity regions at positions } 2 \text { to } 15,28 \text { to } 35 \text {, } \\
\text { and } 203 \text { to } 221 \text { and two tetratricopeptide repeat (TPR) regions } \\
\text { below the threshold at positions } 78 \text { to } 111 \text { and } 112 \text { to } 145 \text {. } \\
\text { Presence of the TPR after finding TPR containing homologous } \\
\text { chaperones by CDART. }\end{array}$ & 69.7 & 74.0 & DQ299391 \\
\hline & copD1 & Chlamydia outer protein D1 & $\begin{array}{l}440 \text { AA, nine regions of low complexity at the following } \\
\text { positions: } 14-35,62-102,134-148,158-169,183-197 \text {, } \\
202-217,228-309,335-345 \text {, and } 396-419 \text {. No similarities } \\
\text { found by CDART. }\end{array}$ & 64.8 & 63.7 & DQ299392 \\
\hline
\end{tabular}


Table III. Continued

\begin{tabular}{|c|c|c|c|c|c|c|}
\hline Cluster & Gene & Protein & Properties and similarities as defined by SMART and CDART & $\begin{array}{l}\text { \% identity with } \\
\text { Cp. pneumoniae }\end{array}$ & $\begin{array}{l}\text { \% identity with } \\
\text { C. trachomatis }\end{array}$ & $\begin{array}{c}\text { Accession } \\
\text { number }\end{array}$ \\
\hline \multirow[t]{4}{*}{ Cluster 3} & $\operatorname{sct} N$ & $\begin{array}{l}\text { Secretion and cellular } \\
\text { translocation protein } \mathrm{N}\end{array}$ & $\begin{array}{l}442 \text { AA, small low complexity region at position } 99 \text { to } 111 \text {, } \\
\text { large ATPase associated activity (AAA) domain at position } 163 \\
\text { to } 345 \text {. Identity and similarity higher than } 90 \% \text { for all species } \\
\text { within the Chlamydiaceae. }\end{array}$ & 77.4 & 76.8 & DQ299393 \\
\hline & ca037 & Hypothetical protein & $\begin{array}{l}282 \text { AA, low complexity regions at positions } 70 \text { to } 87,106 \text { to } \\
125 \text {, and } 252 \text { to } 274 \text {. }\end{array}$ & 65.0 & 62.7 & DQ299396 \\
\hline & $\operatorname{sct} Q$ & $\begin{array}{l}\text { Secretion and cellular } \\
\text { translocation protein } \mathrm{Q}\end{array}$ & $\begin{array}{l}371 \text { AA, low complexity region at position } 288 \text { to } 304 \text {. } \\
\text { Similarity with the flagellar biosynthesis protein FliM. }\end{array}$ & 65.1 & 63.0 & DQ299394 \\
\hline & $\operatorname{sct} C$ & $\begin{array}{l}\text { Secretion and cellular } \\
\text { translocation protein C }\end{array}$ & $\begin{array}{l}\text { First } 710 \text { bp of the } s c t C \text { gene were missed. } 672 \text { AA, low } \\
\text { complexity regions at positions } 256 \text { to } 265 \text { and } 283 \text { to } 290 \text {. In } \\
\text { the same region, a RhoGAP (GTPase activator protein for } \\
\text { Rho-like GTPases) domain was found (position 131-297). } \\
\text { SMART found a TPR domain below the threshold at position } \\
429 \text { to } 462 \text {, which was confirmed using CDART. As for SctN, } \\
\text { very high conservation of SctC among Chlamydiaceae. }\end{array}$ & 76.8 & 76.1 & DQ299395 \\
\hline \multirow[t]{2}{*}{$\begin{array}{l}\text { Non } \\
\text { clustered }\end{array}$} & inc $A$ & $\begin{array}{l}\text { Inclusion membrane } \\
\text { protein A }\end{array}$ & $\begin{array}{l}380 \mathrm{AA} \text {, transmembrane regions at positions } 69 \text { to } 91 \text { and } 96 \text { to } \\
115 \text { and a coiled- coil at position } 224 \text { to } 296 \text {. A t_SNARE } \\
\text { domain, related with intracellular vesicle fusion, endocytosis } \\
\text { and exocytosis, was found at position } 254 \text { to } 318 \text {. }\end{array}$ & 46.3 & 38.5 & DQ299386 \\
\hline & cadd & $\begin{array}{l}\text { Chlamydia protein } \\
\text { associated with death } \\
\text { domains }\end{array}$ & $\begin{array}{l}271 \text { AA, stop codon at position } 14 \text {, which was absent in the } C p \text {. } \\
\text { caviae and } C p \text {. abortus orthologues. Transmembrane domain at } \\
\text { position } 5 \text { to } 27 \text {, low complexity region at position } 244 \text { to } 265 \text {. } \\
\text { Death domain at position } 86 \text { to } 178 \text {, less significant than the } \\
\text { threshold, and RasGEFN (Guanine nucleotide exchange factor } \\
\text { for Ras-like GTPases) domain (position } 15 \text { to } 140 \text { ). }\end{array}$ & 52.7 & 57.4 & DQ299397 \\
\hline
\end{tabular}


SctW, an additional protein band of approximately $80 \mathrm{kDa}$ was observed from $15 \mathrm{~min}$ p.i. onwards, as well as two additional bands at $45-50 \mathrm{kDa}$. For SctC, the $99.5 \mathrm{kDa}$ signal was accompanied by clear signal at $50 \mathrm{kDa}$ and a clear band at $\sim 80 \mathrm{kDa}$. For SctN, only a weak signal at $48.3 \mathrm{kDa}$ could be observed at $48 \mathrm{~h}$ p.i. (data not shown). A protein band of approximately $53 \mathrm{kDa}$ accompanied the IncA signal of $41.8 \mathrm{kDa}$.

\subsection{Intracellular localization of SctW, SctC, SctN, and IncA}

To determine the localization of the chosen T3S proteins, both immunofluorescence and immuno electron microscopy were carried out. SctW was detected from 25 to $50 \mathrm{~h}$ p.i. and the signal was most intense from 30 to $35 \mathrm{~h}$ p.i. SctW staining was associated with the inclusion with a rim like pattern of more intense fluorescence at the periphery of the inclusion (Fig. 2A). Immuno electron microscopy showed labeling of both the reticulate body and the inclusion membrane (Fig. 3G). Non-specific background labeling was not observed (Fig. 3A). SctC was detected from 15 to $30 \mathrm{hp}$.i. and the fluoresent signal for $C p$. psittaci and SctC colocalized inside the host cell (Fig. 2B), which was confirmed by immuno electron microscopy (Fig. 3C, 3D). The fluorescent signal for SctC was, in contradiction to the one for SctW, more evenly distributed throughout the inclusion. SctN was detected from $15 \mathrm{~h}$ p.i. until $50 \mathrm{~h}$ p.i., with a maximum signal at 30 to $35 \mathrm{~h}$ p.i. Like for SctW, SctN staining was more intense at the periphery of the inclusion (Fig. 2C). IncA was expressed from $22 \mathrm{~h}$ till $45 \mathrm{~h}$ p.i. and was associated with both $C p$. psittaci and the inclusion membrane (Fig. 3F).

\subsection{T3S gene expression analysis}

After proving the existence of a $C p$. psittaci T3SS, RT-PCR assays were carried out on Cp. psittaci 92/1293 RNA to investigate the transcription of the 14 currently full-length sequenced $C p$. psittaci T3S genes and of 14 T3S genes for which full-length sequences could not be obtained but for which consensus RT-PCR primers could be designed (sctV, sct $U$, sct $T$, copB1, sctD, pkn5, incB, inc C, scc3, copB2, copD2, cap1, tarp, ca530). RTPCR primers were first checked by standard PCR and qPCR on Cp. psittaci 92/1293 genomic DNA. All primer couples, except the ones for $i n c B$ and $\operatorname{cop} B 2$ yielded a specific PCR product of the expected size and melting temperature. IncB and $c o p B 2$ were therefore excluded from the expression studies. The obtained $\mathrm{Ct}$ values were used as a measure for the initial (c)DNA and RNA template quantity and quantification was performed for a total of 28 reactions (26 chlamydial T3S genes, 16S rRNA and the internal MS2 spike).

Expression was detected for 24 of 26 examined T3S genes as sctT and ca530 were apparently not expressed. Statistical analysis confirmed the absence of significant differences between mRNA expression ratios from two independent infection experiments (Student's T-test). The ANOVA test revealed significant upregulation of gene expression along the time axis. An overview of the upregulation time points before and after $16 \mathrm{~S}$ rRNA normalization is given in Table IV.

For gene cluster 1, comprising sccl, sct W, $s c t V$, and $s c t U$, expression results revealed $s c t W$ and its putative chaperone sccl as well as sctV to follow the same transcription pattern with peak expressions at $12 \mathrm{~h}$ p.i. during the middle phase of the developmental cycle, and less prominent peak expressions at $36 \mathrm{~h}$ p.i. For $s c t V$, an additional minor expression peak was present at $4 \mathrm{~h}$ p.i. The $s c t U$ gene transcription seemed to follow the same pattern, with the exception of a first peak at $16 \mathrm{~h}$ p.i. instead of $12 \mathrm{~h}$ p.i.

For gene cluster 2, represented by sctJ, $s c t L, s c t R, \operatorname{sct} S, \operatorname{sct} T, \operatorname{scc} 2, \operatorname{cop} B 1$, and $\operatorname{cop} D 1$, results were as follows. SctJ, encoding the FliF homologue of the flagellar rotor (MS ring), was constitutively highly expressed throughout the developmental cycle, reaching a peak expression at $36 \mathrm{~h}$ p.i. SctL and $s c t R$ principally showed the same gene expression pattern, with a primary mRNA peak at $12 \mathrm{~h}$ p.i. during the mid-cycle period, and a second one at $36 \mathrm{~h}$ p.i. during the late stage of 

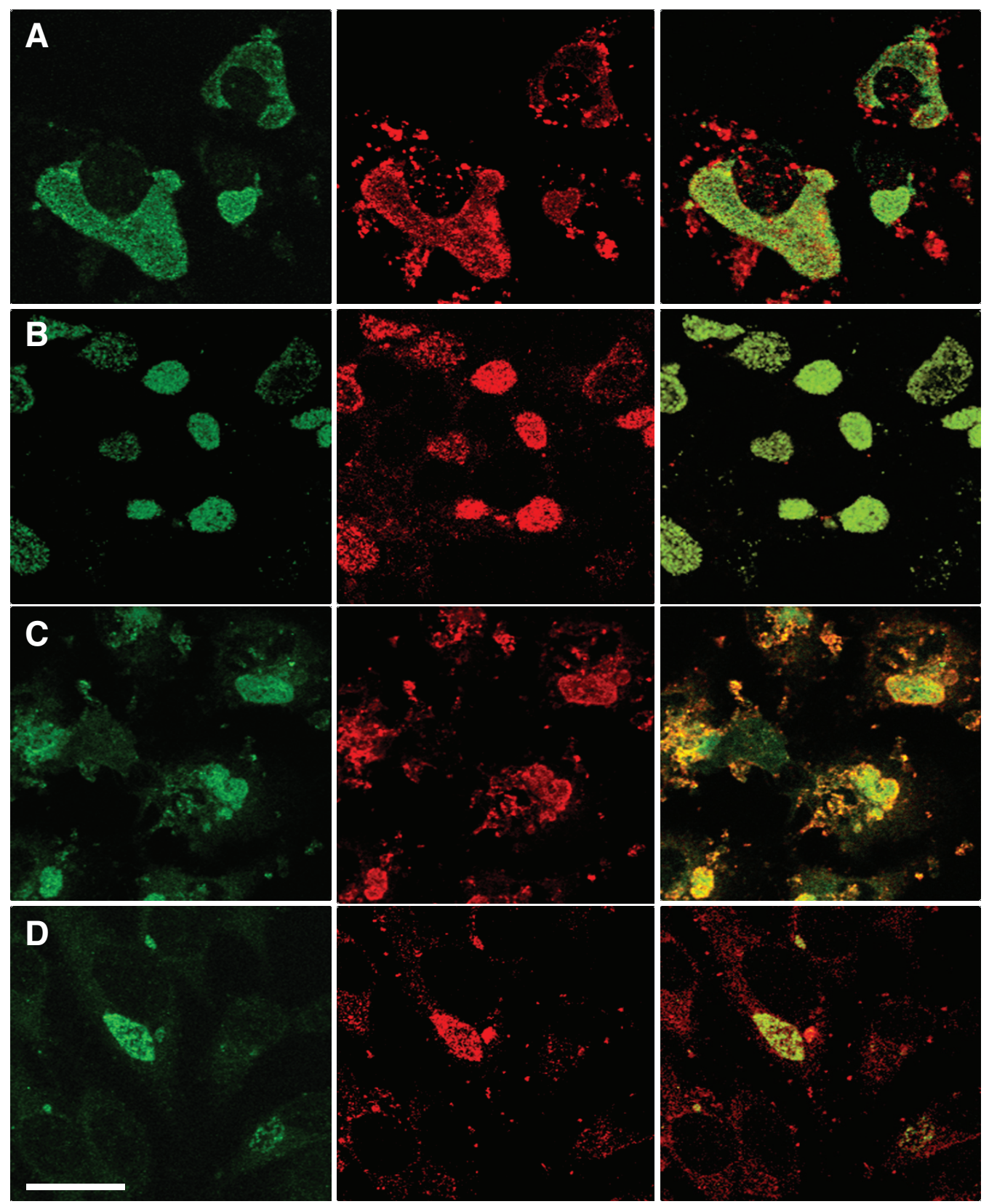

Figure 2. Cellular localization of SctW, SctC, SctN, and IncA $(\times 600)$ at $28 \mathrm{~h}$ p.i. of BGM-cells. Staining was performed as described in experimental procedures and representative confocal images are shown. From left to right: $C$ p . psittaci inclusion staining, T3S protein staining and merged images. A: SctW staining was predominantly found in the inclusion with more intense staining at the periphery. B: SctC colocalized with the bacteria inside the host cell. C: for SctN a more intense staining of the periphery of the inclusion could be observed. D: IncA staining was associated with both $C p$. psittaci and the outer boundaries of the inclusion. The bar represents $25 \mu \mathrm{m}$ (a color version of this figure is available online at www.vetres.org). 

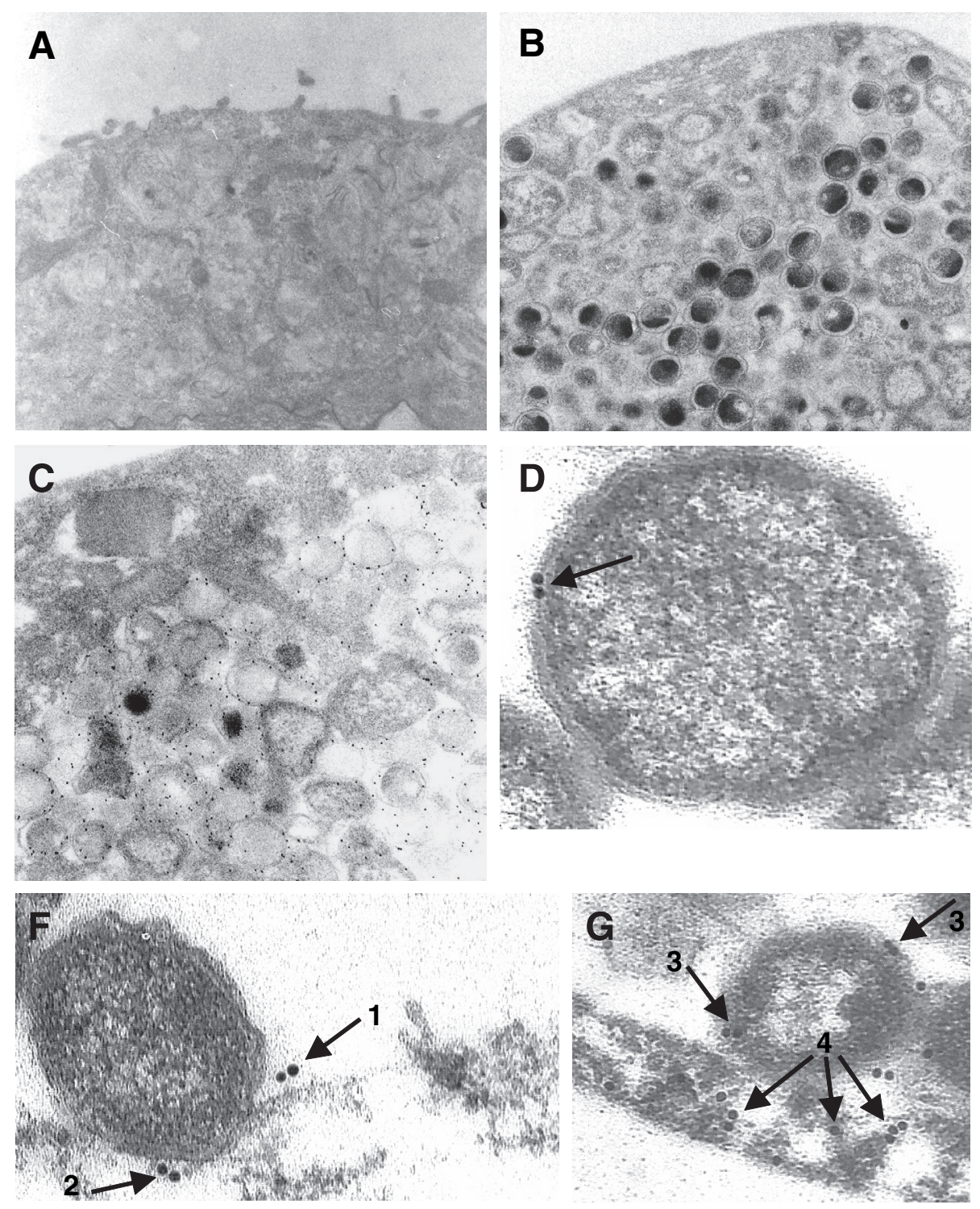

Figure 3. Ultrastructural localization of SctW, SctC, SctN, and IncA at different time points p.i. of BGMcells. Immuno electron microscopy was performed as described in the materials and methods section. Representative images are shown. A: uninfected BGM monolayer stained with the antibodies generated in rabbits $(\times 3200)$. B: infected BGM monolayer stained with rabbit pre-immunization serum $(\times 3200)$. C: overall view of the SctC staining $(\times 3200)$ at $30 \mathrm{~h}$ p.i. of BGM-cells. D: BGM culture, $30 \mathrm{~h}$ p.i. with Cp. psittaci. Gold labelling (arrow) of SctC, part of the secretin in the outer membrane of a reticulate body ( $\times 8900)$. F: BGM culture, $22 \mathrm{~h}$ p.i. with $C$ p. psittaci. Gold labelling of secreted IncA (arrow 1) and localization of the effector protein in the inclusion membrane (arrow 2), $(\times 11500)$. G: BGM culture, $48 \mathrm{~h}$ p.i. with $C p$. psittaci. SctW gold labelling. Notice the presence of SctW in both the reticulate body (arrow 3 ) and the inclusion membrane (arrow 4, which at the end of the developmental cycle apparently dissolves [4] near the host cell membrane $(\times 8900)$.

Page 12 of 18 (page number not for citation purpose) 
the developmental cycle. $S c c 2$ was expressed at $6 \mathrm{~h}$ p.i., and only slightly upregulated at $12 \mathrm{~h}$ p.i. Its close neighbour copDl on the other hand was upregulated at $6 \mathrm{~h}, 12 \mathrm{~h}$, and especially $36 \mathrm{~h}$ p.i.

$S c t D, s c t Q$ and $s c t C$, all belonging to the T3S gene cluster 3 , were first upregulated at $12 \mathrm{~h}$ p.i. and subsequently at $36 \mathrm{~h}$ p.i., although the latter signal was rather faint compared to the one observed during the middle stage of the developmental cycle. SctN does not seem to be strongly upregulated and its largest relative expression was already observed at $1 \mathrm{~h}$ p.i. Expression of $c a 037$ peaked at $36 \mathrm{~h}$ p.i.

A pool of incA mRNA seems to exist as maximal relative incA expression was observed at 5 min p.i., with a second strong signal at $10 \mathrm{~h}$ p.i. This was not the case for inc $C$, reaching its maximal expression level at $16 \mathrm{~h}$ p.i., which was however still very low in comparison to incA expression levels. The capl and scc3 genes showed their highest relative expression level at $1 \mathrm{~h}$ p.i. Expression of tarp peaked at $36 \mathrm{~h}$ p.i.

\section{DISCUSSION}

\subsection{Sequencing of $C p$. psittaci T3S genes}

A detailed discussion of the results of the in silico analysis of sequenced $C p$. psittaci $\mathrm{T} 3 \mathrm{~S}$ genes can be found in the Appendix (available online only at www.vetres.org).

\subsection{Sequencing, expression, and intracellular localization of SctW, SctN, SctC, and IncA}

SctW of $C$. trachomatis shows similarity to Yersinia YopN and would - like in Yersinia spp. - be an important regulator of T3S in the absence of contact with a susceptible host cell. In immunoblotting $C p$. psittaci SctW ( $\sim 40 \mathrm{kDa})$ could be detected from $15 \mathrm{~min}$ on, with expression peaking at $30 \mathrm{~h}$ p.i. (Fig. 1). This is in agreement with $C$. trachomatis SctW expressed at $20 \mathrm{~h}$ p.i. [9]. On the contrary, Lugert et al. [23] could not detect Cp. pneumoniae SctW until 48 h p.i. Possible explanations for the two additional bands at 45$50 \mathrm{kDa}$ are phosphorylation as 30 possible phosphorylation sites were predicted by the
NetPhos server, and association with a chaperone protein [32]. The $\sim 80 \mathrm{kDa}$ band could represent a SctW dimer, although, unlike for $C$. trachomatis SctW [9], no coiled-coil domain could be predicted. Previous immunofluorescence experiments in $C$. trachomatis and $C p$. pneumoniae and present studies in $C p$. psittaci showed inclusion membrane and inclusion body associated SctW [9,16,23]. This supports the hypothesis of SctW being a soluble protein blocking the transmembrane channel $[9,33]$.

SctC proteins are the only T3SS proteins that are clearly localized in the outer membrane and they have no flagellar homologue. In Yersinia, the SctC homologue YscC is absolutely required for a functional T3SS [26]. Membrane localization was confirmed for $C$. trachomatis [12]. As such, membrane localization was also expected for Cp. psittaci SctC, considering the high homology between the chlamydial SctC proteins and the presence of two transmembrane domains. For $C$. trachomatis, polymorphic SctC bands have been observed in immunoblotting, but unfortunately their molecular weights were not mentioned [12]. Similar findings were obtained for $C$ p . psittaci SctC. A $100 \mathrm{kDa}$ protein was expected and detected from $22 \mathrm{~h}$ p.i. on as well as proteins of $\sim 50 \mathrm{kDa}$ and $\sim 80 \mathrm{kDa}$ (Fig. 1). The physical relevance of the observed polymorphisms remains to be elucidated. It is however possible that the full length protein is processed in fragments of less than $100 \mathrm{kDa}$. In both immunofluorescence and immuno electron microscopy, SctC colocalized between $15 \mathrm{~h}$ and $30 \mathrm{~h}$ p.i. with the bacteria in the inclusion, supporting its structural function in the T3SS.

SctN probably delivers the energy for the chlamydial T3SS as $C$. trachomatis SctN contains two nucleotide binding domains [9] and shows high homology with the Yersinia ATPase YscN [44] and other bacterial ATPases. As SctN is highly conserved in Chlamydiaceae, it was no surprise to find a large ATPase associated activity domain in $C p$. psittaci SctN. Lugert et al. [23] found $C p$. pneumoniae SctN in Hep-2 cell lysate at $48 \mathrm{~h}$ p.i. using immunoblotting. SctN was very difficult to detect in $C p$. psittaci, as only a weak 
Table IV. T3S gene expression patterns for $C p$. psittaci in BGM cells. Total RNA from $2 \times 10^{5}$ BGM cells inoculated with $C p$. psittaci $92 / 1293$ at an MOI of 13 was isolated at 0, 5, 15, 30, and 60 min p.i. and subsequently every two hours until $24 \mathrm{~h}$ p.i., and finally at 36,48 , and $60 \mathrm{~h}$ p.i. The experiments were performed twice and all samples were tested in duplicate. For each gene the timepoint at which a specific PCR product was first detected is provided (timepoint at which the absolute copy number without 16S rRNA normalization was higher than 100). In order to describe the gene expression profile for each of the genes under study, the timepoint where maximal significant upregulation of the genes was observed is given in the fourth column, as determined by an ANOVA with post hoc analysis along the time axis (both Tukey HSD and Tukey-b test, $P<0.01$ ). The last column describes further significant upregulation time points after 16S rRNA normalization, in order of their importance.

\begin{tabular}{|c|c|c|c|c|}
\hline Cluster & Gene & $\begin{array}{c}\text { First } \\
\text { detection }\end{array}$ & $\begin{array}{l}\text { Major upregulation } \\
\text { timepoints }\end{array}$ & $\begin{array}{l}\text { Secondary timepoints } \\
\text { of upregulation }\end{array}$ \\
\hline \multirow[t]{4}{*}{ Cluster 1} & $s c c 1$ & $12 \mathrm{~h}$ & $12 \mathrm{~h}$ & $36 \mathrm{~h}$ \\
\hline & $\operatorname{sct} W$ & $12 \mathrm{~h}$ & $12 \mathrm{~h}$ & $60 \mathrm{~h}$ and $36 \mathrm{~h}$ \\
\hline & $\operatorname{sct} V$ & $12 \mathrm{~h}$ & $36 \mathrm{~h}$ & $12 \mathrm{~h}$ and $4 \mathrm{~h}$ \\
\hline & $\operatorname{sct} U$ & $16 \mathrm{~h}$ & $16 \mathrm{~h}$ & $36 \mathrm{~h}$ \\
\hline \multirow[t]{8}{*}{ Cluster 2} & sctJ & $5 \mathrm{~min}$ & $36 \mathrm{~h}$ & \\
\hline & $s c t L$ & $12 \mathrm{~h}$ & $12 \mathrm{~h}$ & \\
\hline & sctR & $12 \mathrm{~h}$ & $12 \mathrm{~h}$ & $36 \mathrm{~h}$ \\
\hline & $s c t S$ & $/^{\mathrm{a}}$ & / & / \\
\hline & sct $T$ & / & / & / \\
\hline & $s c c 2$ & $6 \mathrm{~h}$ & $6 \mathrm{~h}$ & $12 \mathrm{~h}$ \\
\hline & copB1 & $36 \mathrm{~h}$ & $36 h^{b}$ & \\
\hline & copD1 & $1 \mathrm{~h}$ & $36 \mathrm{~h}$ & $6 \mathrm{~h}$ and $12 \mathrm{~h}$ \\
\hline \multirow[t]{6}{*}{ Cluster 3} & $s c t D$ & $12 \mathrm{~h}$ & $12 \mathrm{~h}$ & $36 \mathrm{~h}$ \\
\hline & $\operatorname{sct} N$ & $1 \mathrm{~h}$ & $1 \mathrm{~h}^{\mathrm{b}}$ & \\
\hline & $c a 037$ & $10 \mathrm{~h}$ & $36 \mathrm{~h}$ & $60 \mathrm{~h}$ and $12 \mathrm{~h}$ \\
\hline & sct $Q$ & $12 \mathrm{~h}$ & $12 \mathrm{~h}$ & $36 \mathrm{~h}$ \\
\hline & pkn5 & $24 \mathrm{~h}$ & $*$ & $*$ \\
\hline & $\operatorname{sct} C$ & $12 \mathrm{~h}$ & $12 \mathrm{~h}$ & $36 \mathrm{~h}$ \\
\hline \multirow{10}{*}{$\begin{array}{l}\text { Non- } \\
\text { clustered }\end{array}$} & inc $C$ & $16 \mathrm{~h}$ & $16 \mathrm{~h}$ & \\
\hline & incB & NT & NT & NT \\
\hline & incA & $5 \min$ & $5 \min$ & $10 \mathrm{~h}$ \\
\hline & $\operatorname{scc} 3$ & $1 \mathrm{~h}$ & $1 \mathrm{~h}$ & $12 \mathrm{~h}$ \\
\hline & сорB2 & NT & NT & NT \\
\hline & copD2 & / & / & / \\
\hline & cap1 & $1 \mathrm{~h}$ & $1 \mathrm{~h}$ & \\
\hline & tarp & $12 \mathrm{~h}$ & $36 \mathrm{~h}$ & \\
\hline & ca530 & / & / & / \\
\hline & cadd & $10 \mathrm{~h}$ & $12 \mathrm{~h}$ & $60 \mathrm{~h}$ \\
\hline Normalizing & $16 S$ rRNA & $5 \mathrm{~min}$ & - & - \\
\hline
\end{tabular}

${ }^{a}$ No signal observed.

${ }^{\mathrm{b}}$ Faint signal.

*No upregulation following $16 \mathrm{~S}$ rRNA normalization.

NT: not tested.

Page 14 of 18 (page number not for citation purpose) 
signal at the expected molecular mass was noticed at $48 \mathrm{~h}$ p.i. in immunoblotting. This could be due to the fact that a cross-reacting $C p$. pneumoniae antibody was used and that cross-reactive epitopes were destroyed during SDS-PAGE. A clear staining of the chlamydial inclusion was noticed in immunofluorescence using the same antibody (Fig. 2), confirming that indeed $\mathrm{SctN}$ was present. In $C p$. pneumoniae, $\mathrm{SctN}$ was shown to be associated with the cytoplasmic side of the inner bacterial membrane [23]. This is in accordance with the present immunofluorescence results demonstrating SctN inside $C p$. psittaci inclusions.

Three different phosphorylated forms of $C p$. caviae IncA could be visualised in immunoblotting, each with a different molecular weight [7,29]. Although the NetPhos server predicted 27 possible phosphorylation sites for $C p$. psittaci IncA (data not shown), only one band of $41.8 \mathrm{kDa}$ could be detected. The protein band observed at $53 \mathrm{kDa}$ might therefore reflect the association of IncA with a host protein located at the place of its insertion in the inclusion membrane, as interaction between IncA and host-proteins has been reported for $C p$. caviae [29]. Immuno electron microscopy confirmed the predicted membrane associated topology.

\subsection{T3S gene expression analysis}

The expression of 26 T3S genes was studied during the $C p$. psittaci developmental cycle in BGM cells and results were compared to T3S gene expression studies in C. trachomatis and $C p$. pneumoniae. Generally accepted temporal expression categories, based on when specific chlamydial mRNA are first detected, were defined as early ( 1.5 to $8 \mathrm{~h}$ ), middle ( 12 to $18 \mathrm{~h}$ ), and late (by $24 \mathrm{~h}$ ) [33]. The early-cycle expression category contains predominantly macromolecular synthesis genes and genes encoding products that modify the inclusion membrane, whereas intermediary metabolism and structural components are major representatives of mid-cycle genes. Typical late-cycle genes include those involved in terminal differentiation of RB to EB [31].
$C p$. psittaci sccl, sctW, and sctV gene expression was detected from $12 \mathrm{~h}$ onwards, while $s c t U$ expression was observed from $16 \mathrm{~h}$ p.i. onwards. The general trend for all studies in Chlamydiaceae $[12,23]$ is the finding of coding mRNA from mid-cycle (12h p.i.) onwards, which implicates that T3S cluster 1 proteins are not de novo synthesized during the early stages of the developmental cycle.

$C p$. psittaci sctJ expression already occurred 5 min p.i. and sct J was constitutively expressed throughout the developmental cycle. This is in contradiction with results obtained for $C$. trachomatis and $C p$. pneumoniae, where SctJ mRNA was first detected from mid-cycle onwards ( $12 \mathrm{~h}$ and $8 \mathrm{~h}$ p.i., respectively) [12, 31, 33]. However, SctJ is constitutively present in $C$. trachomatis infected HeLa cell lysate collected from $1 \mathrm{~h}$ to $18 \mathrm{~h}$ p.i. [12], supporting the presence of a functional T3SS apparatus prior to de novo synthesis of its different components. For sctS and sct $T$ no expression could be observed in $C p$. psittaci, which is in contrast with the results for $C$. trachomatis and $C p$. pneumoniae [12,23,33]. Cp. psittaci copB1 and copD1 transcripts appeared at $36 \mathrm{~h}$ and $1 \mathrm{~h}$ p.i. respectively. In $C$. trachomatis however, expression of both genes was first noticed at $20 \mathrm{~h}$ p.i. [12], while in Cp. pneumoniae, copBl was expressed at $48 \mathrm{~h}$ p.i. [23]. Because no time points were examined between $24 \mathrm{~h}$ and $48 \mathrm{~h}$ p.i. in the study of Lugert et al. [23], it cannot be excluded that $C p$. pneumoniae expresses copB1 earlier, like in the present study. However, middle to late cycle expression of putative translocator components is strange, since one would expect that they are necessary to guide effector proteins through the inclusion membrane. On the other hand, CopB 1 and CopD1 proteins are detected in lysed purified $C$. trachomatis EB, again illustrating that a fully functional T3SS is present at the early stages of the chlamydial developmental cycle [12].

$C p$. psittaci sct $N$ was relatively highly expressed at $1 \mathrm{~h}$ p.i. and subsequently at rather small quantities during the whole developmental cycle. In $C$. trachomatis and Cp. pneumoniae, $\operatorname{sct} N$ expression was detected at $12 \mathrm{~h}$ and 
$8 \mathrm{~h}$ p.i., respectively, and the expression level seemed to be higher than for $C p$. psittaci SctN $[12,23,31,33]$. However, as SctN is supposed to be the T3SS energizer, it is unlikely that $C p$. psittaci SctN would be produced in smaller quantities compared to $C$. trachomatis or $C p$. pneumoniae SctN. Moreover, immunofluorescence clearly showed the presence of SctN in chlamydial inclusions (this study). Maybe $C p$. psittaci sct $N$ mRNA is more rapidly degraded, resulting in lower detection. Further examination is needed.

When we turn to the expression results of (putative) effector proteins, inc $C$ expression was first detected at $16 \mathrm{~h}$ p.i. This is in contrast with results obtained for $C$. trachomatis and $C p$. pneumoniae, where inc $C$ transcript was already detected at $2 \mathrm{~h}$ p.i. $[12,23]$. The $C p$. psittaci incA gene was first expressed at $5 \mathrm{~min}$ p.i., followed by a transcription upregulation at $10 \mathrm{~h}$ p.i. A comparable result was obtained for $C p$. pneumoniae, where incA expression was also found from the first investigated time point ( $2 \mathrm{~h}$ p.i.) on. $S c c 3$ expression was already noticed $1 \mathrm{~h}$ after infection with $C p$. psittaci, analogous to what was found for Cp. pneumoniae [33]. This corresponds to the protein's putative chaperone function in SctW secretion [32]. Class I accessible protein-1 (Cap1) is inserted into the inclusion membrane of $C$. trachomatis possibly after $\mathrm{T} 3 \mathrm{~S}$ and is able to stimulate MHC class I $\mathrm{CD}^{+}{ }^{+} \mathrm{T}$-cells [13]. The coding gene is expressed during the early stages $(4 \mathrm{~h}$ p.i.) of the $C$. trachomatis developmental cycle [2]. Current results show that the capl gene is expressed in Cp. psittaci, reaching a maximal relative expression level at $1 \mathrm{~h}$ p.i. Transcription of the Tarp encoding gene was found to occur late during the $C p$. psittaci developmental cycle (Tab. IV). This implicates that Tarp might have the same function as in C. trachomatis where it plays an important role in chlamydial attachment and that Tarp is stored in the EB until attachment to a new host cell.

The T3S protein translation study revealed the expression of SctW, SctC, SctN and IncA present in the lumen of the inclusion (SctC and SctN) or associated with the inclusion membrane (SctW and IncA). The present gene expression study clearly demonstrates the transcription of structural components of the $C p$. psittaci $92 / 1293$ T3SS from $8 \mathrm{~h}$ to $12 \mathrm{~h}$ p.i. indicating that the T3SS is possibly newly assembled from mid-cycle on. Genes encoding effectors and putative T3S related proteins were expressed early or late during the developmental cycle. In this way, we are the first to provide evidence for the presence of a $C p$. psittaci T3SS most likely assisting in the establishment of an optimal intracellular environment for bacterial growth. Further research is required to examine the role of $\mathrm{T} 3 \mathrm{~S}$ in the context of infection biology possibly unique to $C p$. psittaci. Currently, experiments addressing this issue are in progress.

Acknowledgments. Delphine Beeckman is a research assistant of the Research Foundation - Flanders (FWO - Vlaanderen) and this institution is acknowledged for providing a Ph.D. grant. Tom Geens was supported by a Ph.D. grant from Ghent University (Grant 01113401). The authors wish to thank Raimond Lugert for his kind gift of the anti-SctN antibody. Kris Gevaert and Joel Vandekerckhove from the Department of Medical Protein Research (VIB Proteomics Core Facility) are acknowledged for mass spectroscopy. Sarah De Munck, Bart De Cock, and Dries Helderweirt are acknowledged for technical assistance.

\section{REFERENCES}

[1] Andersen A.A., Vanrompay D., Avian chlamydiosis, Rev. -Off. Int. Epizoot. (2000) 19:396-404.

[2] Balsara Z.R., Roan N.R., Steele L.N., Starnbach M.N., Developmental regulation of Chlamydia trachomatis class I accessible protein-1, a CD8+ T cell antigen, J. Infect. Dis. (2006) 193:1459-1463.

[3] Blom N., Gammeltoft S., Brunak S., Sequence and structure-based prediction of eukaryotic protein phosphorylation sites, J. Mol. Biol. (1999) 294:13511362.

[4] Clifton D.R., Dooley C.A., Grieshaber S.S., Carabeo R.A., Fields K.A., Hackstadt T., Tyrosine phosphorylation of the chlamydial effector protein Tarp is species specific and not required for recruitment of actin, Infect. Immun. (2005) 73:38603868.

[5] Clifton D.R., Fields K.A., Grieshaber S.S., Dooley C.A., Fischer E.R., Mead D.J., Carabeo R.A., Hackstadt T., A chlamydial type III translocated protein is tyrosine-phosphorylated at the site of entry and associated with recruitment of actin, Proc. Natl. Acad. Sci. USA (2004) 101:10166-10171. 
[6] Cornelis G.R., The Yersinia Ysc-Yop "type III" weaponry, Nat. Rev. Mol. Cell Biol. (2002) 3:742-752.

[7] Delevoye C., Nilges M., Dautry-Varsat A., Subtil A., Conservation of the biochemical properties of IncA from Chlamydia trachomatis and Chlamydia caviae: oligomerization of IncA mediates interaction between facing membranes, J. Biol. Chem. (2004) 279:4689646906.

[8] Douglas A.L., Hatch T.P., Expression of the transcripts of the sigma factors and putative sigma factor regulators of Chlamydia trachomatis L2, Gene (2000) 247:209-214.

[9] Fields K.A., Hackstadt T., Evidence for the secretion of Chlamydia trachomatis CopN by a type III secretion mechanism, Mol. Microbiol. (2000) 38:1048-1060.

[10] Fields K.A., Hackstadt T., The chlamydial inclusion: escape from the endocytic pathway, Annu. Rev. Cell Dev. Biol. (2002) 18:221-245.

[11] Fields K.A., Hackstadt T., The Chlamydia type III secretion system: structure and implications for pathogenesis, in: Bavoil P.M., Wyrick P.B. (Eds.), Chlamydia: genomics and pathogenesis, Horizon Bioscience, Wymondham, Norfolk, 2006, pp. 219 233.

[12] Fields K.A., Mead D.J., Dooley C.A., Hackstadt T., Chlamydia trachomatis type III secretion: evidence for a functional apparatus during early-cycle development, Mol. Microbiol. (2003) 48:671-683.

[13] Fling S.P., Sutherland R.A., Steele L.N., Hess B., D’Orazio S.E., Maisonneuve J., Lampe M.F., Probst P., Starnbach M.N., CD8+ T cells recognize an inclusion membrane-associated protein from the vacuolar pathogen Chlamydia trachomatis, Proc. Natl. Acad. Sci. USA (2001) 98:1160-1165.

[14] Geens T., Desplanques A., Van Loock M., Bönner B.M., Kaleta E.F., Magnino S., Andersen A.A., Everett K.D.E., Vanrompay D., Sequencing of the Chlamydophila psittaci ompA gene reveals a new genotype, $\mathrm{E} / \mathrm{B}$, and the need for a rapid discriminatory genotyping method, J. Clin. Microbiol. (2005) 43:2456-2461.

[15] Geer L.Y., Domrachev M., Lipman D.J., Bryant S.H., CDART: protein homology by domain architecture, Genome Res. (2002) 12:1619-1623.

[16] Herrmann M., Schuhmacher A., Muhldorfer I., Melchers K., Prothmann C., Dammeier S. Identification and characterization of secreted effector proteins of Chlamydophila pneumoniae TW183, Res. Microbiol. (2006) 157:513-524.

[17] Ho T.D., Starnbach M.N., The Salmonella enterica serovar Typhimurium-encoded type III secretion systems can translocate Chlamydia trachomatis proteins into the cytosol of host cells, Infect. Immun. (2005) 73:905-911.

[18] Hogan R.J., Mathews S.A., Mukhopadhyay S., Summersgill J.T., Timms P., Chlamydial persistence: beyond the biphasic paradigm, Infect. Immun. (2004) 72:1843-1855.

[19] Hueck C.J., Type III protein secretion systems in bacterial pathogens of animals and plants, Microbiol. Mol. Biol. Rev. (1998) 62:379-433.

[20] Kalman S., Mitchell W., Marathe R., Lammel C., Fan J., Hyman R.W., Olinger L., Grimwood J., Davis R.W., Stephens R.S., Comparative genomes of Chlamydia pneumoniae and C. trachomatis, Nat. Genet. (1999) 21:385-389.

[21] Laemmli U.K., Cleavage of structural proteins during the assembly of the head of bacteriophage T4, Nature (1970) 227:680-685.

[22] Letunic I., Copley R.R., Pils B., Pinkert S., Schultz J., Bork P., SMART 5: domains in the context of genomes and networks, Nucleic Acids Res. (2006) 34:D257-D260.

[23] Lugert R., Kuhns M., Polch T., Gross U., Expression and localization of type III secretionrelated proteins of Chlamydia pneumoniae, Med. Microbiol. Immunol. (2004) 193:163-171.

[24] Pallen M.J., Beatson S.A., Bailey C.M., Bioinformatics, genomics and evolution of non-flagellar typeIII secretion systems: a Darwinian perspective, FEMS Microbiol. Rev. (2005) 29:201-229.

[25] Perkins D.N., Pappin D.J., Creasy D.M., Cottrell J.S., Probability-based protein identification by searching sequence databases using mass spectrometry data, Electrophoresis (1999) 20:3551-3567.

[26] Plano G.V., Straley S.C., Mutations in yscC, yscD, and yscG prevent high-level expression and secretion of $\mathrm{V}$ antigen and Yops in Yersinia pestis, J. Bacteriol. (1995) 177:3843-3854.

[27] Read T.D., Brunham R.C., Shen C., Gill S.R., Heidelberg J.F., White O., et al., Genome sequences of Chlamydia trachomatis MoPn and Chlamydia pneumoniae AR39, Nucleic Acids Res. (2000) 28:1397-1406.

[28] Read T.D., Myers G.S., Brunham R.C., Nelson W.C., Paulsen I.T., Heidelberg J., et al., Genome sequence of Chlamydophila caviae (Chlamydia psittaci GPIC): examining the role of nichespecific genes in the evolution of the Chlamydiaceae, Nucleic Acids Res. (2003) 31:2134-2147.

[29] Rockey D.D., Grosenbach D., Hruby D.E., Peacock M.G., Heinzen R.A., Hackstadt T., Chlamydia psittaci IncA is phosphorylated by the host cell and 
is exposed on the cytoplasmic face of the developing inclusion, Mol. Microbiol. (1997) 24:217-228.

[30] Rockey D.D., Scidmore M.A., Bannantine J.P., Brown W.J., Proteins in the chlamydial inclusion membrane, Microbes Infect. (2002) 4:333-340.

[31] Shaw E.I., Dooley C.A., Fischer E.R., Scidmore M.A., Fields K.A., Hackstadt T., Three temporal classes of gene expression during the Chlamydia trachomatis developmental cycle, Mol. Microbiol. (2000) 37:913-925.

[32] Slepenkin A., de la Maza L.M., Peterson E.M. Interaction between components of the type III secretion system of Chlamydiaceae, J. Bacteriol. (2005) 187:473-479.

[33] Slepenkin A., Motin V., de la Maza L.M., Peterson E.M., Temporal expression of type III secretion genes of Chlamydia pneumoniae, Infect. Immun. (2003) 71:2555-2562.

[34] Stephens R.S., Kalman S., Lammel C., Fan J., Marathe R., Aravind L., et al., Genome sequence of an obligate intracellular pathogen of humans: Chlamydia trachomatis, Science (1998) 282:754-759.

[35] Subtil A., Delevoye C., Balana M.E., Tastevin L., Perrinet S., Dautry-Varsat A., A directed screen for chlamydial proteins secreted by a type III mechanism identifies a translocated protein and numerous other new candidates, Mol. Microbiol. (2005) 56:16361647.

[36] Subtil A., Parsot C., Dautry-Varsat A., Secretion of predicted Inc proteins of Chlamydia pneumoniae by a heterologous type III machinery, Mol. Microbiol. (2001) 39:792-800.

[37] Thomson N.R., Yeats C., Bell K., Holden M.T., Bentley S.D., Livingstone M., et al., The
Chlamydophila abortus genome sequence reveals an array of variable proteins that contribute to interspecies variation, Genome Res. (2005) 15:629-640.

[38] Troisfontaines P., Cornelis G.R., Type III secretion: more systems than you think, Physiology (Bethesda) (2005) 20:326-339.

[39] Van Loock M., Vanrompay D., Herrmann B., Vander S.J., Volckaert G., Goddeeris B.M., Everett K.D., Missing links in the divergence of Chlamydophila abortus from Chlamydophila psittaci, Int. J. Syst. Evol. Microbiol. (2003) 53:761-770.

[40] Vanrompay D., Andersen A.A., Ducatelle R., Haesebrouck F., Serotyping of European isolates of Chlamydia psittaci from poultry and other birds, J. Clin. Microbiol. (1993) 31:134-137.

[41] Vanrompay D., Charlier G., Ducatelle R., Haesebrouck F., Ultrastructural changes in avian Chlamydia psittaci serovar A-, B-, and D-infected Buffalo Green Monkey cells, Infect. Immun. (1996) 64:1265-1271.

[42] Vanrompay D., Ducatelle R., Haesebrouck F., Diagnosis of avian chlamydiosis: specificity of the modified Gimenez staining on smears and comparison of the sensitivity of isolation in eggs and three different cell cultures, Zentralblatt Veterinarmedizin Reihe B (1992) 39:105-112.

[43] Wilson P.A., Phipps J., Samuel D., Saunders N.A., Development of a simplified polymerase chain reaction-enzyme immunoassay for the detection of Chlamydia pneumoniae, J. Appl. Bacteriol. (1996) 80:431-438.

[44] Woestyn S., Allaoui A., Wattiau P., Cornelis G.R., YscN, the putative energizer of the Yersinia Yop secretion machinery, J. Bacteriol. (1994) 176:15611569. 